\title{
Protective role of Phyllantus niruri extract on serum lipid profiles and oxidative stress in hepatocytes of diabetic rats
}

\author{
Nwanjo, H. U. ${ }^{1}$, Oze, G. ${ }^{2}$, Okafor, M. C. ${ }^{2}$, Nwosu, D. ${ }^{1}$ and Nwankpa, P. ${ }^{2}$ \\ ${ }^{1}$ Department of Medical Lab. Science, Imo State University, Owerri, Imo State. \\ ${ }^{2}$ Department of Medical Biochemistry, Imo State University, Owerri, Imo State.
}

\begin{abstract}
Accepted 13 April, 2007
Diabetes mellitus has been associated with lipid abnormalities and oxidative stress. Some phytochemical properties have been shown to possess antioxidant activities, improving the effects of oxidative stress on diabetes. This present investigations confirmed that untreated diabetic rats were associated with lipid abnormalities as indicated by high levels of total- and LDL-cholesterol, triacylglycerols and low levels of HDL-cholesterol and phospholipids, compared to non-diabetic rats (control). The aqueous extract of Phyllanthus niruri significantly normalized the serum lipids levels. The study also showed that untreated diabetic rats were subjected to oxidative stress as indicated by significantly abnormal activities of their scavenging enzymes (superoxide dismutase and catalase and significantly low levels of non-enzymic antioxidants (vitamin C, vitamin E and reduced glutathione) in liver and plasma when compared with controls and in the extent of lipid peroxidation (increased malondialdehyde levels) in plasma and liver cells. The aqueous extract of $P$. niruri possessed antioxidant activities as shown by increased activities of enzymic and non-enzymic antioxidants and decrease in malondialdehyde levels.
\end{abstract}

Key words: Oxidative stress, Phyllanthus niruri, lipids and hepatocytes.

\section{INTRODUCTION}

Diabetes mellitus is a metabolic disease characterized by hyperglycaemia and glycosuria due to absolute or relative insulin deficiency (Aguwa, 1996). It is a multifactorial disease, which is also characterized by lipoprotein abnormalities (Scoppola et al., 2001). These traits are hypothesized to damage cell membranes which results in elevated production of reactive oxygen species (ROS). This generation of oxygen-free-radicals during cellular metabolism, and by certain environmental factors, including life style, appears to play a critical role in the pathogenesis of diabetes mellitus (Hartnelt et al., 2000). Hyperglycemia, the main symptoms of diabetes, not only increases the production of ROS but also affects antioxidant (Uchimura

*Corresponding authors E-mail: harrisonnwanjo@yahoo.co.uk. Tel: +234-8033525389. et al., 1999). Diabetes has also been associated with an increased risk for developing premature arteriosclerosis due to increase in triacylglyceroles and low-density lipoprotein levels and decrease in light density lipoprotein levels (Bierman, 1992).

Recently, there has been increasing interest in the use of traditional medicinal plants in management of various disease conditions especially diabetes mellitus. Phyllanthus niruri, commonly called "Enyikwonwa" in Igbo land of the south Eastern part of Nigeria belongs to the family Euphorbiaceae. P. niruri has been claimed to be hypoglycaemic and hepatoprotective by the traditional healers or herbalist in Eastern part of Nigeria and also by some researchers (Taylor, 2003; Mazumder et al., 2005). It is of medicinal importance for numerous ailments like dysentery, influenza, viginitis, tumours, diabetes, diuretics, jaundice, kidney stones, dyspepsia, antihepatotoxic, antihepatitis- $B$, antihyperglycaemic and also antiviral and an- 
tibacterial (Chopra et al., 1986).

Although $P$. niruri has been investigated for its various medicinal properties, detailed evaluation of its anti-lipoproteinaemic, antioxidant and lipid peroxidative potentials in diabetic rats are still lacking. In this study, we evaluated the antioxidant potentials of an aqueous extract of $P$. niruri and its effects on enzymic and non-enzymic antioxidants activities in hepapocytes of streptozotocin-induced rats. We also evaluated their effects on lipid peroxidation in liver by measuring malondialdehyde (MDA) Levels and on cholesterols and triacylglycerols levels in serum.

\section{MATERIALS AND METHODS}

\section{Chemicals}

Streptozotocin (STZ), thiobarbituric acid (TBA), butylated hydroxytoluene (BNT), reduced glutathione (GSH), 2,2,- dipyridyl, xynol orange, aspartic acid, alanine, a-ketoglutarate, 2,4-dinitro phenyl hydrazine (DNPH), 5,5-dithiobis-2-nitrobenzoic acid (DTNB) were obtained from Sigma Chemical Co (St Louis, MO-USA). The rest of the chemical utilized were of analytical grade and were obtained from local firms (Nigeria).

\section{Plant materials}

The plant $P$. niruri was collected in the month of June, 2006 from the Imo State University Campus, Owerri, Nigeria. The plant was taxonomically identified and authenticated by $\mathrm{Dr}$ S. E. Okeke, Head, Department of Plant Science and Biotechnology, Imo State University, Owerri. The voucher samples were preserved in the university herbarium for future reference.

\section{Preparation of the aqueous plant extract}

The entire plant of $P$. niruri was sun dried for ten days before the final drying in an oven at $50^{\circ} \mathrm{C}$ for $24 \mathrm{~h}$. The dried plants were powdered in both manual grinder and electric grinder. $15 \mathrm{~g}$ of the $P$. niruri powder was soaked with $350 \mathrm{ml}$ of distilled water in a beaker and the mixture shaken on the laboratory bench for $24 \mathrm{~h}$ before filtering. The filtrate was then evaporated by hot-air oven treatment at $40-50^{\circ} \mathrm{C}$. Appropriate weights of the residue were prepared in distilled water to obtain the various concentration used for the experiments.

\section{Animals}

Male Wistar rats $(200-300 \mathrm{~g})$ bred in the Animal House of College of Medicine and Health Sciences, Imo State University, Owerri were used in this study. They were housed in stainless steel cages and kept in a room where a $12 \mathrm{~h}$ light/dark cycle was maintained. They were allowed free access to water and feed diet (product of Pfizer Nigeria Ltd) ad libitum throughout the period of the experiment.

\section{Induction of diabetes in rats}

After one week of acclimatization, the rats were subjected to a $16 \mathrm{~h}$ fast. Diabetes was induces with a single intraperitoneal injection of streptozotocin (STZ) at a dose of $65 \mathrm{mg} / \mathrm{kg}$ body weight. The STZ was freshly dissolved in citrate buffer $(0.01 \mathrm{~m}, \mathrm{pH} 4.5)$ (Ozsoy-
Sacan, 2000). The injection volume was prepared to contain 1.0 $\mathrm{ml} / \mathrm{kg}$ (Murali et al., 2002). After 5 days, blood glucose levels were measure and the animals with a concentration of more than 230 $\mathrm{mg} / \mathrm{dl}$ were classified as diabetic (Cetto et al., 2000).

\section{Experimental design}

Twenty four male Wistar rats were used in this study. The rats were randomized and divided into four groups of six animals each.

Group 1: Normal, received normal saline solution $(0.9 \% \mathrm{NaCl}, 5$ $\mathrm{ml} / \mathrm{kg}$ ).

Group 2: Diabetic, received STZ (65 mg/kg body weight) once

Group 3: Diabetic, receive STZ (65 mg/kg body weight) once before receiving aqueous extract of $P$. niruri $(120 \mathrm{mg} / \mathrm{kg}$ body weight)

Group 4: Diabetic received STZ (65 mg/kg body weight) once before receiving aqueous extract of $P$. niruri $(240 \mathrm{mg} / \mathrm{kg}$ body weight).

After 14 days of treatment, all the rats were decapitated after fasting for $16 \mathrm{~h}$. Blood was collected in two different tubes i.e. one with fluoride oxalate anticoagulant for plasma separation and another without anticoagulant to separate serum for various biochemical estimations. The livers were dissected out and cleared off blood. They were immediately transferred to ice-cold containers containing $0.9 \% \mathrm{NaCl}$ and homogenized in $0.1 \mathrm{~N}$ Tris-Hcl buffer $(\mathrm{pH}$ 7.4), and used for the estimation of malondialdehyde (MDA), reduced glutathione (GSH), superoxide dismutase (SOD) and catalase (CAT) activity.

\section{Measurement of blood glucose levels}

The body weight and blood glucose levels were measured at the beginning and end of the experiment. Blood samples were obtained by tail vein puncture of both the normal and STZ-induced diabetic rats. Blood glucose levels were determined using a glucometer (Lifescan Johnson and Johnson Company, Milipitas, CA).

\section{Acute toxicity tests}

The acute toxicity of the extract was tested using 30 Wistar rats divided into 5 groups of 6 rats each, with each group receiving graded dose (250 - $1500 \mathrm{mg} / \mathrm{kg}$ body weight, intraperitoneally) of the aqueous extract of $P$. niruri as described by Ghosh (1984). After administration of the extract the rats were observed for toxic effects after $48 \mathrm{~h}$ treatment. The toxicological effects were observed in terms of mortality expressed as $L D_{50}$. The number of animals dying during a period was noted. The $\mathrm{LD}_{50}$ of the extract was estimated from the graph of percentage (\%) mortality (converted to probit) against log-dose of the extract, probit 5 being $50 \%$ (Litch field et al., 1959).

\section{Estimation of serum lipids}

Extraction of lipids from serum carried out according to the procedure of Folch et al. (1957) by using chloroform-methanol $(2: 1, \mathrm{v} / \mathrm{v})$ mixture. From this total cholesterol LDL- and HDL-cholesterol triacylglyceroles and phospholipids were estimated as earlier described (Nwanjo, 2005; Nwanjo and Ojiako, 2005).

\section{Estimation of lipid peroxidation}

Lipid peroxidation in plasma and liver was estimated colorimetrically 
Table 1. Mean values of body weight and blood glucose in experimental and control rats.

\begin{tabular}{|l|ccc|cc|}
\hline \multirow{2}{*}{ Treatment } & \multicolumn{3}{|c|}{ Body weight (g) } & \multicolumn{2}{c|}{ Fasting blood glucose (mg/dl) } \\
\cline { 2 - 6 } & Initial & Final & change & Initial & Final \\
\hline Control (Group 1) & $180.8 \pm 6.2$ & $198.82 \pm 8.4$ & $18.2 \pm 4.0^{* \star}$ & $96.34 \pm 12.8$ & $82.8 \pm 10.5$ \\
Diabetic Group II & $182.2 \pm 4.4$ & $158.71 \pm 6.9$ & $-23.49 \pm 3.2$ & $230.56 \pm 20.0$ & $262.4 \pm 32.0$ \\
Diabetic + 120 mg/kg P. niruri (Group III) & $183.4 \pm 6.8$ & $192.26 \pm 5.2$ & $8.86 \pm 2.6^{*}$ & $231.23 \pm 11.6$ & $138.92 \pm 13.2^{\#}$ \\
Diabetic $+240 \mathrm{mg} / \mathrm{kg}$ P. niruri (Group IV) & $180.9 \pm 10.8$ & $196.98 \pm 112$ & $16.08 \pm 4.4^{\star \star}$ & $231.89 \pm 13.2$ & $97.9 \pm 6.8^{\#}$ \\
\hline
\end{tabular}

*Significantly different from diabetic rats (group II) $(P<0.05)$.

**Significantly different from group II and group III $(P<0.05)$.

\# Significantly different from initial fasting blood glucose $(P<0.05)$.

by measuring malondialdehyde (MDA) by the method of Nichans and Samualson (1968). In brief, $0.1 \mathrm{ml}$ of plasma was treated with 2 $\mathrm{ml}$ of (1:1:1 ratio) TBA-TCA-HCL reagent (TBA $0.37 \%$ : $0.25 \mathrm{~N} \mathrm{HCL:}$ $15 \% \mathrm{TCA}$ ) and placed in water bath for $15 \mathrm{~min}$, cooled and centrifuged and then clear supernatant was measured at $535 \mathrm{~nm}$ against reference blank.

\section{Estimation of enzymic antioxidants}

Superoxide dismutase (SOD) activity was determined by the modified method of NADH-phenazinemethosulphate-nitrobluete-trazolium formazon inhibition reaction spectrophotometrically at $560 \mathrm{~nm}$ (Kakkar et al., 1984). A single unit of enzyme was expressed as $50 \%$ inhibition of NBT (nitroblue tetrazolium) reduction $/ \mathrm{min} / \mathrm{mg}$ protein.

Catalase (CAT) was assayed calorimetrically as described by Sinha (1972) using dichromate-acetic acid reagent (5\% potassium dichromate and glacial acetic acid were mixed in 1.3 ratio). The intensity was measured at $620 \mathrm{~nm}$ and the amount of hydrogen peroxide hydrolyzed was calculated for the catalase activity.

\section{Estimation of non-enzymic antioxidants}

Reduced glutathione (GSH) was determined by the method of Ellman (1959). $1 \mathrm{ml}$ of supernatant $(0.5 \mathrm{ml}$ plasma/ $0.5 \mathrm{ml}$ liver homogenate precipitated by $2 \mathrm{ml}$ of $5 \%$ TCA) was taken and $0.5 \mathrm{ml}$ of Ellman's reagent $(0.0198 \%$ DTNB in $1 \%$ sodium citrate) and $3 \mathrm{ml}$ of phosphate buffer ( $\mathrm{pH}$ 8.0) were added. The colour developed was read at $412 \mathrm{~nm}$.

Vitamin C (ascorbic acid) concentration was measured by Omaye et al. (1979) method. To $0.5 \mathrm{ml}$ of plasma/ $0.5 \mathrm{ml}$ liver homogenate, $1.5 \mathrm{ml}$ of supernatant, $0.5 \mathrm{ml}$ of DNPH reagent ( $2 \% \mathrm{DNPH})$ and $4 \%$ thiourea in $9 \mathrm{~N}$ sulphuric acid) was added and incubated for $3 \mathrm{~h}$ at room temperature. After incubation $2.5 \mathrm{ml}$ of $8.5 \%$ sulphuric acid was added and colour developed was read at $530 \mathrm{~nm}$ after $30 \mathrm{~min}$.

Vitamin $E$ ( $\alpha$-tocopherol) was estimated by the method of Desai (1984). Vitamin E was extracted from plasma/liver homogenate by addition of $1.6 \mathrm{ml}$ ethamol and $2.0 \mathrm{ml}$ petroleum ether to $5.0 \mathrm{ml}$ plasma and centrifuged. The supernatant was separated and evaporated. To the residue, $0.2 \mathrm{ml}$ of $0.2 \% 2$,2-dipyridyl, $0.2 \mathrm{ml}$ of $0.5 \%$ ferric chloride was added and kept in dark for $5 \mathrm{~min}$, an intense red colour layer obtained on addition of $4 \mathrm{ml}$ butanol was read at 520 $\mathrm{nm}$.

\section{Statistics}

Statistical evaluation of data was performed by using one-way analysis of variance ANOVA followed by Duncan's multiple range test (DMRT) (Duncan, 1957).

\section{RESULTS}

\section{Effect of extract of $\boldsymbol{P}$. niruri on blood glucose levels and body weight changes}

The results of blood glucose levels and body weight changes in normal, STZ-induced diabetic rats and $P$. niruri treated diabetic rats were shown in Table 1. There was a significant $(p<0.01)$ increase in blood glucose levels in STZ-induced diabetic rats (Group II) when compared with normal rats. Administration of aqueous extract of $P$. niruri at a dose of 120 and $240 \mathrm{mg} / \mathrm{kg}$ body weight significantly $(p<0.05)$ decreased blood glucose in STZ induced rats (Group III and IV). The results were found to be in a dose dependent manner.

The body weight in the diabetic group was significantly less $(p<0.05)$ than the normal control which then returned to near normal in diabetic rats treated with aqueous extract of $P$. niruri at a dose of 120 and $240 \mathrm{mg} / \mathrm{kg}$ body weight

\section{Effect of aqueous extract of $P$. niruri on serum lipids}

The changes in the levels of serum lipids in control and experimental rats are illustrated in Table 2 . The total cholesterol, LDL-Cholesterol and triacylglycerol signific-antly increased and HDL-Cholesterol and phospholipids signifycantly decreased in STZ-induced diabetic rats (group II) $(P<0.05)$ when compared with the normal (group I) rats. The aqueous extract of $P$. niruri $(120 \mathrm{mg} / \mathrm{kg}$ and 240 $\mathrm{mg} / \mathrm{kg}$ body weight) offered a significant protection against alteration in the serum lipids of diabetic rats. The results were also dose dependent.

\section{Effects of $\boldsymbol{P}$. niruri aqueous extract on MDA}

The levels of MDA in plasma and liver were significantly $(p<0.05)$ increased in STZ-induced rats as compared to normal rats. Treatment with aqueous extract of $P$. niruri 
Table 2. Mean values of serum lipids in experimental and control rats.

\begin{tabular}{|l|c|c|c|c|c|}
\hline Treatment & $\begin{array}{c}\text { Total-C } \\
\text { (mg/dl) }\end{array}$ & $\begin{array}{c}\text { HDL-C } \\
\text { (mg/dl) }\end{array}$ & $\begin{array}{c}\text { LDL-C } \\
\text { (mg/dl) }\end{array}$ & $\begin{array}{c}\text { TG } \\
\text { (mg/dl) }\end{array}$ & $\begin{array}{c}\text { Phospholipids } \\
\text { (mg/dl) }\end{array}$ \\
\hline Control (Group 1) & $92.1 \pm 8.62^{* *}$ & $46.2 \pm 3.58^{*}$ & $31.99 \pm 2.0^{* *}$ & $69.55 \pm 3.4^{* *}$ & $92.3 \pm 6.5^{*}$ \\
Diabetic (Group II) & $172.5 \pm 9.5$ & $30.2 \pm 4.2$ & $100.68 \pm 4.2$ & $158.1 \pm 8.4$ & $65.1 \pm 3.2$ \\
Diabetic + 120 mg/kg P. niruri (Group III) & $130.66 \pm 10.6^{*}$ & $42.8 \pm 3.6^{*}$ & $66.22 \pm 3.5^{*}$ & $108.2 \pm 5.8^{*}$ & $80.2 \pm 6.1^{*}$ \\
Diabetic + 240 mg/kg P. niruri (Group IV) & $98.9 \pm 9.22^{* *}$ & $37.82 \pm 3.9^{*}$ & $44.66 \pm 3.8^{* *}$ & $82.1 \pm 6.1^{* *}$ & $88.3 \pm 5.6^{*}$ \\
\hline
\end{tabular}

*Significantly different from diabetic rats (Group II) $(\mathrm{P}<0.05)$.

${ }^{* *}$ Significantly different from group II and group III $(P<0.05)$.

Table 3. Mean values of plasma and liver lipid peroxidation in experimental and control rats.

\begin{tabular}{|l|c|c|}
\hline Treatment & Plasma MDA (nmol/ml) & Liver MDA (nmol /mI) \\
\hline Control (Group I) & $2.92 \pm 0.48^{*}$ & $10.42 \pm 2.9^{*}$ \\
Diabetic (Group II) & $6.89 \pm 1.04$ & $25.26 \pm 4.8$ \\
Diabetic + 120 mg/kg P. niruri (Group III) & $4.26 \pm 0.98^{*}$ & $14.48 \pm 3.6^{*}$ \\
Diabetic + 240 mg/kg P. niruri (Group IV) & $3.68 \pm 1.12^{*}$ & $12.87 \pm 4.1^{*}$ \\
\hline
\end{tabular}

${ }^{*}$ Significantly different from the diabetic $(p<0.05)$

Table 4. Mean activities of liver of enzymic antioxidant in both experimental and control rats.

\begin{tabular}{|l|c|c|}
\hline Treatment & Liver SOD (units/mg protein) & Liver CAT (units/mg protein) \\
\hline Control (Group I) & $5.89 \pm 0.56^{*}$ & $70.56 \pm 5.3^{*}$ \\
Diabetic (Group II) & $3.01 \pm 0.58$ & $46.2 \pm 4.6$ \\
Diabetic + 120 mg/kg P. niruri (Group III) & $4.99 \pm 0.42^{*}$ & $62.34 \pm 3.8^{*}$ \\
Diabetic + 240 mg/kg P. niruri (Group IV) & $5.04 \pm 1.21^{*}$ & $65.22 \pm 4.02^{*}$ \\
\hline
\end{tabular}

*Significantly different from the diabetic $(p<0.05)$.

Table 5. Mean values of plasma and liver non-enzymic antioxidant in experimental and control rats.

\begin{tabular}{|l|cc|cc|cc|}
\hline \multirow{2}{*}{ Treatment } & \multicolumn{2}{|c|}{ GSH (mg/dl) } & \multicolumn{2}{c|}{ Vitamin C (mg/dl) } & \multicolumn{2}{c|}{ Vitamin E (mg/dl) } \\
\cline { 2 - 7 } & Plasma & Liver & Plasma & Liver & Plasma & Liver \\
\hline Control (Group I) & $19.82 \pm 0.8^{*}$ & $38.2 \pm 3.5^{*}$ & $1.39 \pm 0.3^{*}$ & $1.28 \pm 0.16^{*}$ & $1.71 \pm 0.2^{*}$ & $0.91 \pm 0.04^{*}$ \\
Diabetic(Groupll) & $10.45 \pm 1.7$ & $19.67 \pm 2.8$ & $0.69 \pm 0.2$ & $0.68 \pm 0.08$ & $0.83 \pm 0.15$ & $0.52 \pm 0.04$ \\
Diabetic $+120 \mathrm{mg} / \mathrm{kg}$ P. niruri (Group III) & $16.12 \pm 0.9^{*}$ & $32.2 \pm 3.4^{*}$ & $1.21 \pm 0.32^{*}$ & $1.25 \pm 0.08^{*}$ & $1.42 \pm 0.13^{*}$ & $0.87 \pm 0.04^{*}$ \\
Diabetic $+240 \mathrm{mg} / \mathrm{kg}$ P. niruri (Group IV) & $18.0 \pm 1.33^{*}$ & $35.8 \pm 2.99^{*}$ & $1.22 \pm 0.29^{*}$ & $1.30 \pm 0.11^{*}$ & $1.61 \pm 0.15^{*}$ & $0.88 \pm 0.3^{*}$ \\
\hline
\end{tabular}

*Significantly different from the diabetic $(p<0.05)$.

resulted in a significantly decrease in the levels of lipid peroxidation products (MDA) in diabetic rats (Table 3 ).

\section{Effects of $P$. niruri aqueous extract on enzymic antioxidant status}

A significant decrease $(P<0.05)$ in the activities of enzymic antioxidants such as superoxide dismutase (SOD) and catalase (CAT) of the liver was noted in STZ-induced diabetic rats when compared with the normal rats. Upon administration of 120 and $240 \mathrm{mg} / \mathrm{kg}$ body weight of aqueous extract of $P$. niruri, the activities of both SOD and CAT were significantly reversed to near normal (Table 4).

\section{Effects of $\boldsymbol{P}$. niruri aqueous extract on non-enzymic antioxidant status}

The levels of plasma and liver vitamins $\mathrm{C}, \mathrm{E}$ and reduced glutathione (GSH) were significantly depleted in STZinduced diabetic rats. Treatment with aqueous extract of $P$. niruri significantly increased the levels of these nonenzymic antioxidants in diabetic rats (Table 5). 


\section{DISCUSSION}

This study demonstrated the hypoglycemic, hypolipidaemic and antioxidant effect of aqueous extract of $P$. niruri in STZ-induced diabetic rats. Streptozotocin induction causes a significant elevation in the level of blood glucose and loss of body weight in rats. In this study we observed that the administrated of aqueous extract of $P$. niruri at the doses of 120 and $240 \mathrm{mg} / \mathrm{kg}$ body weight to diabetic rats not only caused a significant decrease in blood glucose but also has a significant effect in controlling the loss of body weight, which is caused during diabetes. High level of blood glucose, the primary clinical manifestation in diabetes, is associated with certain complications of diabetes. Brownlee et al. (1981) reported that in diabetic there is increase in cholesterol/phospholipids ratio, thereby disrupting membranes fluidity and leading to membrane alteration of function. In agreement with this, we also observed that the levels of serum lipids significantly changed in diabetic rats, suggesting that hyperglycemia has devastating effect on membrane stability and functional state. Similar results were observed in our previous study (Nwanjo, 2005). Administration of aqueous extract of $P$. niruri at doses of 120 and $240 \mathrm{mg} / \mathrm{kg}$ body weight showed protection against serum lipid changes in STZ-induced diabetic rats. The activities were found to be in a dose dependent manner.

Membrane lipids succumb easily to deleterious actions of reactive oxygen species (ROS) (Reiter, 1995). ROS induce oxidative tissue damages plays an important role in many clinical disorders such as heart disease, diabetes, gout and cancer associated with the peroxidation of cellular lipids, which is determined by measurement of thiobarbituric acid (TBA)-reactive substance. The concentration of lipid peroxidation products may reflect the degree of oxidative stress in diabetes. It has been reported previously (Baynes, 1991; Kakkar et al., 1995) that in tissues and blood of rats with STZ- induced diabetes, malondialdehyde, one of the by-products of lipid peroxidation is increased. Further, increased level of TBA-reactive substances results in increased levels of oxygen free radicals, which attack the polyunsaturated fatty acid in cell membranes and cause lipid peroxidation. STZ is toxic to pancreatic $\beta$-cells and is thus widely used for induction of experimented diabetes in animals. It can give rise to oxygen free radicals because of the increased blood glucose level in diabetes (Rakieten et al., 1963). The measurement of lipid peroxidation is a convenient method to monitor oxidative damage (Viani et al., 1991). In this study, the increased level of TBA-reactive substances in plasma and liver of STZ-induced diabetic rats reflected the lipid peroxidation as the consequence of oxidative stress caused by increased blood glucose levels in diabetes. Treatment with aqueous extract of $P$. niruri protects the cells through attenuation of lipid peroxidation and decreased the production of free radical derivatives as evident from the deceased levels of plasma and liver TBA-reactive substances. Thus aqueous extract $P$. niruri offered protection against oxidative stress by scavenging of free radicals.

The enzymic antioxidants defense systems are the nature protector against lipid peroxidation. SOD scavenges the superoxide ions produced as cellular by products. SOD is a major defense for aerobic cells in combating the toxic effects of superoxide radicals (McCord et al., 1976). CAT reduces hydrogen peroxide produced by dismutation reaction and prevents generation of hydroxyl radicals thereby protecting the cellular constituents from oxidative damage in peroxisomes. The reduced activities of SOD and CAT in STZ-induced diabetic rats resulted in the accumulation of superoxide radical and $\mathrm{H}_{2} \mathrm{O}_{2}$ respectively, which produce deleterious effects (Mazunder et al., 2005). Administration of aqueous extract of $P$. niruri showed normalization of activities of SOD and CAT in liver of STZ- induced diabetic rats.

Non-enzymic antioxidats such as reduced glutathione (GSH), Vitamin C and Vitamin E play an excellent role in protecting the cells from oxidative damage (Anuradha and Selvam, 1993). GSH is a major endogenous nonenzymic antioxidant which counter balance free radicals mediated damage. It is well established that GSH is involved in the protection of normal cell structure and function by maintaining the redox homeostasis, quenching of free radicals by participation in detoxification reaction and keeps up the cellular levels of the active forms of Vitamin $\mathrm{C}$ and vitamin $\mathrm{E}$ by neutralizing the free radicals. When there is a reduction in GSH the cellular levels of vitamin $C$ and vitamin $E$ are closely inter linked to each other (Pari and Amadi, 2005). In agreement with this report, the decreased levels of $\mathrm{GSH}$, vitamin $\mathrm{C}$ and Vitamin E on STZ-induced diabetic rats were observed in this study. Administration of aqueous extract of $P$. niruri to these diabetic rats, maintained the level of nonenzymic antioxidants to near normal by the possible role of this extract in improving the GSH status.

In conclusion, $P$. niruri exhibits strong hypoglycemic and hypolipidamic activities. Our study also showed that aqueous extract of $P$. niruri have antioxidant activity. Therefore aqueous extract of $P$. niruri is suggested to be effective for reducing oxidative stress and free radicalrelated diseases including diabetes.

\section{REFERENCES}

Aguwa CN (1996): Diabetes Mellitus. In therapeutic Basis of clinical pharmacy in the tropics. Optimal Publishers, Enugu, Nigeria, pp 1 453.

Anuradha CV, Selvam R (1993). Effect of oral methionine on tissue lipid peroxidation and antioxidants in alloxan induced diabetic rats J. Nutr Biochem 4: 212-217.

Baynes JW (1991). Role of oxidative stress in development of complications in diabetes. Diabetes. 40: 405-412

Bierman EL (1992). Atherogenesis in diabetes. Arterioscler. Thromb. 12: 647-656.

Brownlee M, Cerami A (1981). The biochemistry of the complication of diabetes mellitus. Ann Rev. Biochem. 50: 385-432. 
Cetto AA, Weidonfeld H, Revilla MC, Sergio IA (2000) Hypoglycaemic effect of Equisetum mriochaetum aerial parts on STZ-diabetic rats. J. Ethnopharmacol. 72: 129-133.

Chopra RN, Nayar SL, Chopra IC (1986) Glossary of Indian medicinal plants CSIR, New Delhi. Catholic press. Ranchi, India,

Desai ID (1984). Vitamin E analysis method for animal tissues methods. Enzymology 105: 138-143.

Duncan BD (1957). Multiple range tests for correlated and heteroscedastic means. Biometrics 13: 359-364.

Ellman GC (1959). Tissue sulfhydryl groups. Arch. Biochem. Biophys. 82: $70-77$

Folch J, Less M, Solane SGH (1957). A simple method for isolation and purification of total lipids from animal tissues J. Biol. Chem. 226: 497509.

Ghosh MN (1084). Fundamentals of experimental pharmacology. $2^{\text {nd }}$ ed. Calculta: Scientific Book Agency.

Kakkar P, Das B, Viswanathan PN (1984). A modified spectroscopic assay of superoxide dismutase. Indian Biochem. Biophys. 21:130132.

Kakkar P, Kalra J, Mantha SV, prasad K (1995). Lipid peroxidation and activity of antioxidant enzymes in diabetic rats. Mol. cell. Biochem. 151: 113-119.

Hardnett EM, Stratton RD, Browne RW, Rosner BA, Lanham RJ, Armstrong D (2000). Serum markers of oxidative stress, and severity of diabetic retinopathy. Diabet. care. 23: 234-240.

Litch field JT, Wilcoxon F (1959). Determination of acute toxicity tests. J. Pharmacol. Exp. Ther. 96: 99-113.

Mazunder UK, Gupta M, Rajeshwar Y (2005). Antihyperglycaemic effect and antioxidant potential of Phyllantus niruri (Euphorbiaceae) in streptozotocin induced diabetic rats. Eur. Bull. Drug Res. 13 (1): 1523.

McCord JM, Keele BB, Fridovich I Jr. (1976). An enzyme based theory of obligate anaerobiosis.

The physiological functions of superoxide dismutase. Proc. Natl. Acad. Sci. USA. 68: 1024-1027.

Meneghini R (1988). Genotoxicity of active oxygen species in mammalian cells. Mutat. Res. 195:215-230.

Murali B, Upadhyaya UM, Goyal RK (2002). Effect of chronic treatment with Enicostemma littorate in non-insulin dependent diabetic (NIDDM) rats. J. Ethnopharmacol. 81:199-204.

Nichans WG, Sannelson D (1968). Formation of malondialdehyde from phospholipids arachidonate during microsomal lipid peroxidation. Eur. J. Biochem 6:126-130.
Nwanjo HU (2005). Efficacy of aqueous leaf extract of Vernonia amygdalina on plasma lipoprotein and oxidative status in diabetic rat models. Nig. J. Physiol. Sci. 20(1\&2): 39-42.

Nwanjo HU, Ojiako OA (2005). Changes in Plasma Electrolytes and Lipoproteins in Hypertensives on Hydrothiazide Therapy. Nig. J. Biochem. Mol. Biol. 20(1): 31-33.

Omaye ST, Turbull TP, Sanberchich HC (1979). Selected methods for determination of ascorbic acid in cells, tissues and fluids. Methods, Enzymol. 6:3-11.

Ozsoy-Sacan O (2000). Effects of chard (Beta vulgaris L. varcicla) extract on pancreatic $\beta$-cells in STZ-diabetic rats: morphological and biochemical study. J. ethnopharmacol. 73: 251-259.

Pari I, Amadi RD (2005). Protective role of tetrahydrocurcumin (THC) an active principle of turmeric on chloroquine induced hepatotoxicity in rats. J. Pharm. Pharmaceut. Sci. 8(1): 115-123.

Rakieten N, Rakieten ML, Nadkarni MV (1963). Studies on the diabetogenic action of streptozotocin. Cancer Chemother. Rep. 29: 91-98.

Reiter, R.J. (1995). Oxidative processes and antioxidative defuse mechanisms in the aging brain. FASEB, 9: 526-533.

Scoppola A, Montecchi FR, Meqinger G, Lala A (2001). Urinary mevalonate excretion rate in type 2 diabetes: role of metabolic control. Atherosclerosis. 156: 357-36.

Sinha KA (1972). Colorimetric assay of catalase. Ann. Biochem. 47: 389-394 Taylor $L$ (2003). Herbal secrets of the rainforest. $2^{\text {nd }}$ Edition. Sage Press Inc Nig. pp 34

Uchimura K, Nagasaka A, Hayashi R, Makino M, Nagata M, Kakizawa H, Kobayashi T, Fujiwara K, Kato T, Iwase K, Shinohara R, Kato K, Itoh $M$ (1999). Changes in suproxide dismutase activities and myoloperioxdase activities in leukocytes from patients with diabetes mellitus. J. Diabetes complications 13: 264-270.

Viani P, Cervato G, Fiorilli A, Cestaro B (1991). Age related difference in synapatozomal peroxidative damage and membrane properties. $\mathrm{J}$. Neurochem 15: 253-258. 